\title{
DESIGN OPTIMISATION OF ROTARY TILLER BLADE TOWARDS SERVICE LIFE ENHANCEMENT
}

\author{
*Subrata Kumar Mandal ${ }^{1}$, Basudeb Bhattacharyya ${ }^{2}$, Somenath Mukherjee ${ }^{3}$ and \\ Subrata Karmakar ${ }^{4}$
}

${ }^{1,3}$ CSIR-Central Mechanical Engineering Research Institute, Durgapur, West Bengal-713209, India ${ }^{2}$ Indian Institute of Engineering Science and Technology, Shibpur, Howrah, West Bengal-711103, India, ${ }^{4}$ Bidhan Chandra Krishi Viswavidyalaya, Mohanpur, Mohanpur, West Bengal-741252, India

\begin{abstract}
A rotary tiller or rotavator is active tillage equipment used to prepare farmland for sowing seeds, weeding, mixing manure and fertiliser into the soil, crushing soil blocks, etc. Compared with conventional farming, the advantages of this equipment are rapid seedbed preparation and reduced draught. Nowadays, the utilisation rate of rotary tillers has increased. However, the blades are the key component that engages with the soil in the rotary tiller. These blades interact with the soil differently from ordinary ploughs and bear impact loads and high frictional forces, which eventually generate unbalanced and uneven forces on the entire rotary tiller. As a result, the blade faces significant wear. Therefore, it is necessary to optimise the design of the blades to minimise wear and enhance the service life. In this research work, design optimisation was carried out towards improving service life.
\end{abstract}

Keywords: Rotary tiller; Blade; Wear; ANOVA; Tillage

\section{Introduction}

A rotary tiller is a typical unique mechanised tool used to cultivate the land through a series of blades mounted on a rotating shaft. These types of equipment are commonly used to break or treat the soil in fields, lawns, gardens, etc. (Hendrick and Gill, 1971c). The rotary cultivator is a primary tillage machine in many countries, including Bangladesh, India, Nepal, Thailand, Japan, Malaysia, the People's Republic of China, and South Korea [1-4].

Nowadays, due to the flat surface, multiple benefits, and the high efficiency of this tillage machine, rotary tillers in agricultural applications have increased. Using rotary tillers, primary and secondary farming can be combined in one stage [5]. Despite the high energy consumption of rotary tillers, because rotary tillers can complete multiple farming applications in one stage, the total power required by these types of equipment is low [6]. Being an active implement, the power is directly transmitted to the rotary tiller blades via the PTO of a tractor. Hence, the power transmission efficiency is very high, usually in the range of $85-90 \%$. For this reason, the working power of this machine is limited by the available tractor PTO power [7-8]. The

*Corresponding Author - E- mail: subrata.mandal72@gmail.com rotary tiller may have "L", "C", and "J" shaped blades to adapt to various working conditions (Fig. 1). Generally, L-shaped blades are used in Indian rotavators. The blade works very well for trashy conditions, although do not pulverise the soil very much, but this type of blade will cut it and then put those things on the field and virtually try to conserve the field's moisture. It can be seen that Lshaped blades are quite superior to $\mathrm{C}$ or $\mathrm{J}$ type blades in some particular working environments like shabby or bad conditions as they are more effective at killing weeds and they do not crush the soil as much [9]. The commonly used "L-shaped" blade is shown in Fig. 2. Also, in India, the "L-shaped" blades are usually mounted in one flange, and each flange has a pattern of three right-handed and three left-handed blades, as shown in Fig. 3. In a rotary tiller, the rotor usually rotates in the same direction as the tractor wheel.

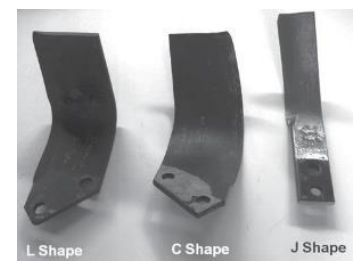

Fig. 1 Different types of rotavator blade [10] 


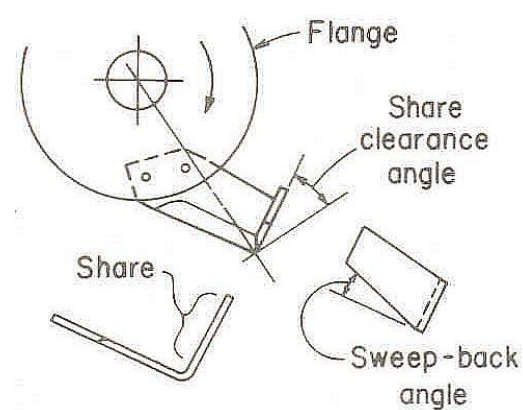

Fig. 2 Three views of an L-shaped blade for rotary tiller [11]

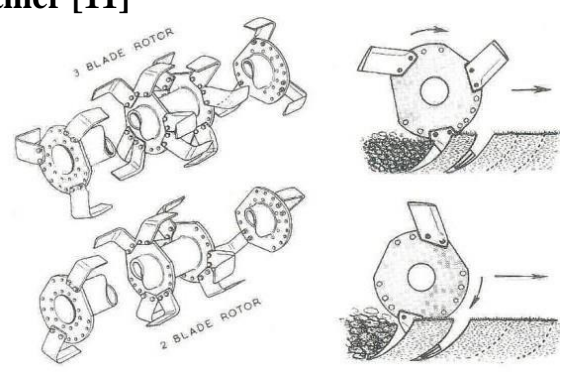

Fig. 3 Rotary tiller rotors with L-type blades showing methods of mounting and cutting [6]

Each blade cuts a section of soil as it moves downward and backwards, as shown in Fig. 4. Most rotary tillers can cut 2 or 3 cuts per revolution. Since the torque is generated for each cut at the highest peak, it is crucial to move the cutting blades in different routes so that the blades have equal angular displacements. Therefore, no two cutting blades can hit the soil simultaneously.

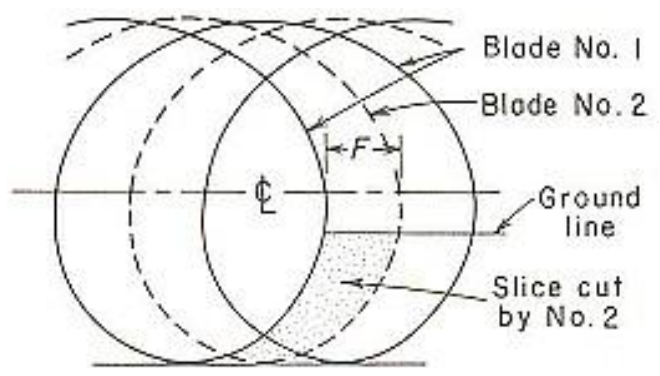

Fig.4 Paths of cutting edges or tips for 2 blades $180^{\circ}$ apart, in relation to forward travel [11]

The quality of work achieved by using a rotary tiller depends not only on the design parameters, but also on the profile of the rotor blades. The rotational speed and forward speed of the rotor will significantly affect the performance of the machine. During farming, soil texture will depend on soil conditions, blade surface- geometry and soil flow dynamics [12]. Depending on the soil conditions, the geometry and speed ratio of the blade, interference under the blade, and uncut soil, there is possibility in resulting soil compaction and high-power consumption. It may be one of the primary sources of vibration, which is the result of the reaction of the soil on the splitter leaves. The correct design of the rotary tiller blades is essential for effective tillage operations [10]. Using the matrix equation, it has been described the blade movement of the rotary tiller and proves that the energy consumption in the rotary tiller can be reduced by improving the blade design [13-14]. It has been found that in corn and barley production systems where uses chisel plows, rotary tillers consume a lot of energy, but compared to traditional farming systems, rotary tillers are more labor-saving [15] Due to the continuous wave impact of the crust/soil/stone, high stress will form in the areas of the blade tip or critical edge. The service life of the rotary tiller is 2400 hours ( 8 years), and the annual use hour is 300 . Usually, the local blade needs to be replaced after 80-200 hours of use. However, the replacement time is about 300350 hours for imported blades. The local and imported blade sets were replaced 23 times and 7 times during the entire service life, respectively. It is estimated that about half a million blades are needed each year for replacement and newly assembled machines [Saxena et al., 2010]. In order to extend the working life and to reduce the expenditure in the farming process, these blades must be appropriately designed [16]. In India, due to various soil conditions in different regions, different blades are used, but it has been seen that most blades face similar problems, such as high wear rates, which will eventually reduce service life or working life. Through proper design according to soil type and soil conditions, the service life of blades can be extended [17]. The design optimisation and manufacturing errors can be minimised by its components design analysis and optimisation, particularly the blades [18]. Therefore, this research aims to design suitable rotary tiller blades by using ANOVA for design optimisation to increase the service life of the blades, thereby reducing the idle time required for occasionally replacing the blades during the soil preparation process.

\section{Materials and Methods}

In order to achieve the purpose of this research, commercial blades mostly used were selected. According to available data, it has been found that depending on the Indian soil conditions; the edges will wear out after 25-40 hours of use in the field. One of the reasons may be the excessive load or stress acting on the surface or tip that exposed most in the soil while in the field usage of rotavator. Wear at the blade tip or cutting plane is taking place because of this excessive loads and Stresses. Although the materials used in the blade have sufficient wear resistance, wear occurs due to the geometry and contour of the blade. The geometry and 3D model of the 
Journal of Manufacturing Engineering, December 2021, Vol. 16, Issue. 4, pp 115-123

original blade are shown in Fig. 5. whereas Fig. 6 describes the important design parameters of the selected rotary tiller's blade. According to the geometric configuration of the blades chosen, twentyfour blades were designed and developed following the L25 orthogonal array and Taguchi method. Table 1 depicts the design parameters of the selected blade considered in this study. Table 2 lists the design parameters of each twenty-four blades.

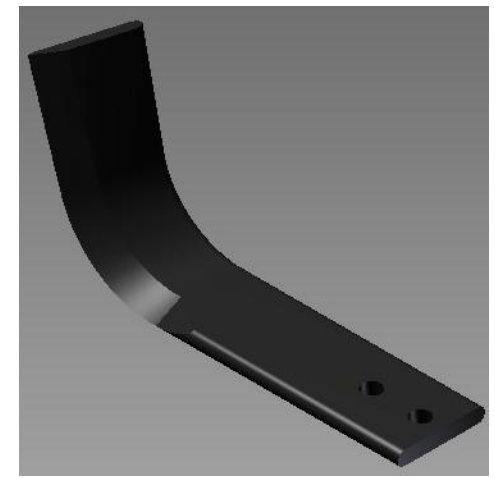

Fig.5 3D model of the original blade

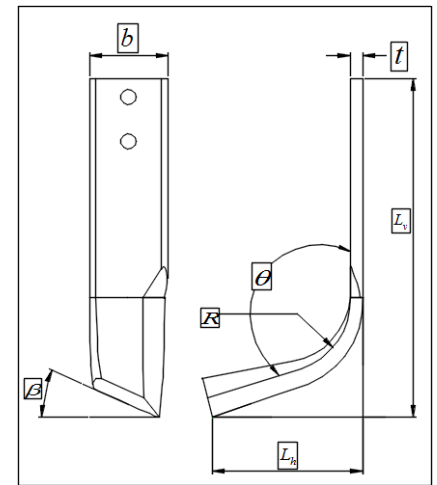

Fig. 6 Important design parameters of an Ltype rotary tillers blade

Table 1 Geometrical Parameters of different blades designed for the study

\begin{tabular}{ll}
\hline Parameters & Notations \\
\hline $\mathrm{b}$ & Blade span, mm \\
$L_{v}$ & Effective vertical length, $\mathrm{mm}$ \\
$L_{h}$ & Blade cutting width, $\mathrm{mm}$ \\
$\mathrm{R}$ & Curvature between $L_{v}$ and $L_{h} \mathrm{~mm}$ \\
$\theta$ & Blade angle, degree \\
$\beta$ & Clearance angle, degree \\
$\mathrm{t}$ & Blade thickness, mm \\
\hline
\end{tabular}

Table 2 Design values of geometrical parameters

\begin{tabular}{lccccccc}
\hline $\begin{array}{l}\text { Blade } \\
\text { No. }\end{array}$ & $\boldsymbol{\beta}^{\mathbf{0}}$ & $\boldsymbol{\theta}^{\mathbf{0}}$ & $\begin{array}{l}\mathbf{w} \\
\mathbf{~ m m}\end{array}$ & $\begin{array}{l}\mathrm{L}_{\mathrm{v}} \\
\mathbf{m m}\end{array}$ & $\begin{array}{l}\mathrm{L}_{\mathrm{h}} \\
\mathbf{~ m m}\end{array}$ & $\begin{array}{l}\mathbf{R} \\
\mathbf{m m}\end{array}$ & $\mathbf{t}(\mathbf{m m})$ \\
\hline 1 & 18 & 97.2 & 40 & 202.1 & 111.9 & 45 & 8 \\
2 & 18 & 102.6 & 40 & 207.6 & 104.9 & 45 & 8 \\
3 & 18 & 108 & 40 & 212.6 & 98.2 & 45 & 8 \\
4 & 18 & 113.4 & 40 & 216.8 & 91.3 & 45 & 8 \\
5 & 18 & 118.8 & 40 & 220.2 & 84.5 & 45 & 8 \\
6 & 19 & 97.2 & 40 & 202.6 & 110.8 & 45 & 8 \\
7 & 19 & 102.6 & 40 & 207.7 & 105.1 & 45 & 8 \\
8 & 19 & 108 & 40 & 212.8 & 98.4 & 45 & 8 \\
9 & 19 & 113.4 & 40 & 217.2 & 91.1 & 45 & 8 \\
10 & 19 & 118.8 & 40 & 220.5 & 84.3 & 45 & 8 \\
11 & 20 & 97.2 & 40 & 202.9 & 110.8 & 45 & 8 \\
12 & 20 & 102.6 & 40 & 208.1 & 105.0 & 45 & 8 \\
13 & 20 & 108 & 40 & 213.1 & 98.3 & 45 & 8 \\
14 & 20 & 113.4 & 40 & 217.5 & 91.0 & 45 & 8 \\
15 & 20 & 118.8 & 40 & 220.9 & 84.1 & 45 & 8 \\
16 & 21 & 97.2 & 40 & 203.3 & 110.8 & 45 & 8 \\
17 & 21 & 102.6 & 40 & 208.4 & 104.9 & 45 & 8 \\
18 & 21 & 108 & 40 & 213.4 & 98.1 & 45 & 8 \\
19 & 21 & 113.4 & 40 & 217.8 & 90.9 & 45 & 8 \\
20 & 21 & 118.8 & 40 & 221.2 & 83.9 & 45 & 8 \\
21 & 22 & 97.2 & 40 & 203.6 & 110.7 & 45 & 8 \\
22 & 22 & 102.6 & 40 & 208.7 & 104.9 & 45 & 8 \\
23 & 22 & 108 & 40 & 213.8 & 98.0 & 45 & 8 \\
24 & 22 & 113.4 & 40 & 218.2 & 90.8 & 45 & 8 \\
25 & 22 & 118.8 & 40 & 221.5 & 83.8 & 45 & 8 \\
\hline & & & & & & &
\end{tabular}

\section{Experiments in a Soil Bin}

In order to obtain critical measurable parameters like cone penetration resistance, soil moisture and torque on the blades etc., a nos. of experiments were conducted on all 25 blades.

\subsection{Soil Bin}

This experimental study was conducted in the controlled soil bin facility available in the Tillage and Traction laboratory of the Department of Agricultural Engineering, situated at Bidhan Chandra Krishi Viswavidyalaya, Mohanpur, Nadia, India. The soil bin ( $20 \mathrm{~m}$ long, $1.8 \mathrm{~m}$ wide, and $0.75 \mathrm{~m}$ deep) was used to provide a repeatable soil condition for the entire experiment. The soil used for the experiments $(55 \%$ sand, $19 \%$ silt, and $26 \%$ clay content) is a sandy-clayloamy soil representing a large proportion of cropgrowing regions in the eastern part of India. The whole bin includes a fixed soil container, transportation system, rotary tiller and soil treatment cart (including road roller), power transmission system, control unit and instruments for measuring different parameters (Fig. 7). The transmission system consists of an $18 \mathrm{hp}, 1450 \mathrm{rpm}$ electric motor, which can be used as a power source for soil treatment units and tool transportation. The tool transport system is equipped with a rotary tiller, soil leveller, road roller, toolbar frame and toolbar. A 
sprinkler is also attached to spray water to the soil to maintain the required moisture content for best results. After each test run, the rotary tiller was used for crushing the soil. The primary purpose of using a roller compactor is to compact the powdery soil in the soil bin to a uniform density. The three-phase electric motor $(3.73 \mathrm{~kW})$ acts as the prime mover of the carriage and rotary tiller. The forward speed is obtained by selecting a suitable gear set for the reducer. The gear set is connected to the input shaft of the rotating drum, and the input shaft of the rotating drum is fixed to the soil treatment vehicle by a stainless-steel rope. A control unit placed outside the soil tank or bin controls the moving direction of the soil treatment truck. The instrument used to measure cone penetration resistance, soil moisture content, and torque on the blade includes an 8-channel data acquisition system connected to a PC to store different parameters.

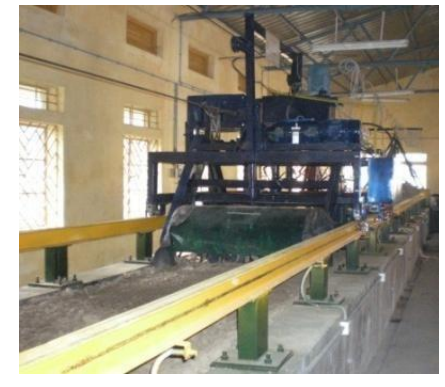

Fig. 7 Complete Soil Bin

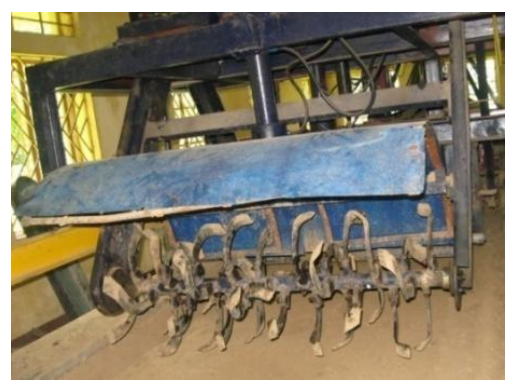

Fig. 8 Rotary tiller with L-type blade

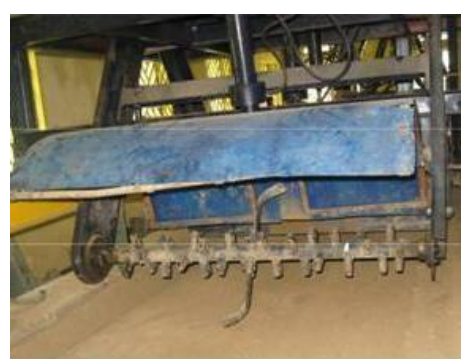

Fig. 9 Blade at $180^{\circ}$ apart
The rotary tiller used in the experiment is shown in Fig. 8. Two rotary tillage blades were mounted on the flange at $180^{\circ}$ out of phase, as shown in Fig. 9. Under reference soil conditions, the designed and manufactured blades operate the tiller at different depths and forward speeds to determine the torque. The detailed specifications of the rotary tiller are working width:1.2 m, the distance between 1 st to last blade: $1.1 \mathrm{~m}$, angular spacing between two blades: $90^{\circ}$ and linear spaces between two blades:0.05 m. Soil moisture of the soil bin was measured by the gravimetric method. The soil bin of the project site is divided into six locations. Soil resistance at six locations was measured with the cone penetrometer attached to the carriage, as shown in Fig. 10. It is usually used to measure soil strength and determine the compacted soil condition. A procedure for using the soil cone penetrometer has been developed [19-20] and indicates the most desirable moisture content for sample collection when the soil is near field capacity.

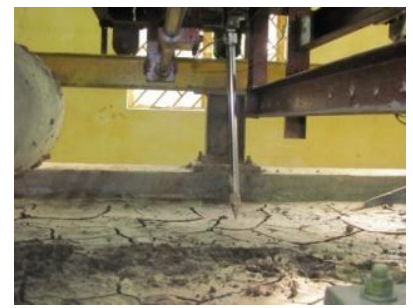

Fig. 10 Cone penetrometer attached with soil processing trolley

Measurements for the force and displacement were taken with a cone penetrometer attached to the carriage at six different locations on the soil bin. It gives different values at soil moisture content and various places in the soil bin. At certain moisture content, cone index values have been taken at six other locations of the soil bin. The cone index (CI) measured values are shown in Table 3. The resulting post-processing diagram is shown in Fig. 11. It seems that the force increases with increasing depth unless, in some cases, the moisture content plays an important role, which reduces the force value.

Table 3 CI values

\begin{tabular}{clll}
\hline $\begin{array}{l}\text { Depth } \\
\text { mm }\end{array}$ & $\begin{array}{l}\text { Penetration } \\
\text { Resistance Force (N) }\end{array}$ & $\begin{array}{l}\text { CI, } \\
\text { MPa }\end{array}$ & $\begin{array}{l}\text { Moisture } \\
\text { content }(\%)\end{array}$ \\
\hline 82.3 & 280.7 & 1.3 & 16.35 \\
60.9 & 720.2 & 3.3 & 12.165 \\
78.8 & 162.2 & 0.744 & 13.3 \\
84.6 & 341.8 & 1.569 & 15.8 \\
78.41 & 170 & 0.781 & 11.89 \\
90.75 & 75.35 & 0.345 & 17.6 \\
\hline
\end{tabular}


Journal of Manufacturing Engineering, December 2021, Vol. 16, Issue. 4, pp 115-123

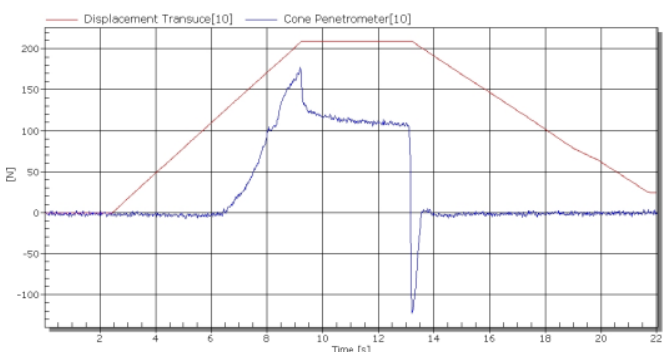

Fig. 11 Post process graph of penetration resistance force and displacement over time

Using the orthogonal array experimental design proposed by Taguchi, the influence of many different parameters on the performance characteristics of a set of enrichment experiments was tested. In this current research, five parameters and five levels of each parameter were selected. The levels of these variables and other values are given in Table 4. Accordingly, $\mathrm{L}^{25}$ orthogonal array tables were set. Thus, the total number of experiments was reduced to 25 . These experiments were designed based on this array. These experiments were conducted to determine the effect of torque on other parameters of the rotary tiller blade in a reference soil condition. After selecting the desired depth and forward travel speed, the implement trolley, i.e., the rotary tiller, was run in the controlled soil bin with an arrangement such that the pulling arm was kept horizontal with the soil bed. Using a pre-calibrated torque sensor, the measurement system continuously acquires data for specific blade torque. These values are presented in Table 5.

Table 4 Parameters of soil bin experiments and their testing levels

\begin{tabular}{l|llllll}
\hline $\begin{array}{l}\text { Design } \\
\text { Parameters }\end{array}$ & Unit & Level 1 & Level 2 & Level 3 & Level 4 & Level 5 \\
\hline $\mathrm{P}_{1}(\beta$, & & $-10 \%$ & $-5 \%$ & 0 & $+5 \%$ & $+10 \%$ \\
\cline { 2 - 7 } $\begin{array}{l}\text { Clearance } \\
\text { angle })\end{array}$ & deg. & 18 & 19 & 20 & 21 & 22 \\
$\begin{array}{l}\mathrm{P}_{2}(\theta, \text { Blade } \\
\text { angle })\end{array}$ & deg. & 97.2 & 102.6 & 108 & 113.4 & 118.8 \\
$\begin{array}{l}\text { Operating } \\
\text { parameters }\end{array}$ & Unit & Level 1 & Level 2 & Level 3 & Level 4 & Level 5 \\
\hline & & $-10 \%$ & $-5 \%$ & 0 & $+5 \%$ & $+10 \%$ \\
\hline $\mathrm{P}_{3}$ (depth, h) & $\mathrm{mm}$ & 75 & 93.75 & 112.5 & 131.2 & 150 \\
\hline $\begin{array}{l}\mathrm{P}_{4} \text { (Forward } \\
\text { velocity, V) }\end{array}$ & $\mathrm{m} / \mathrm{s}$ & 0.5 & 0.94 & 1.35 & 1.78 & 2.2 \\
$\mathrm{P}_{5}$ (Rotary Shaft & $\mathrm{rm}$ & 150 & 180 & 210 & 240 & 270 \\
\begin{tabular}{l}
$\mathrm{RPM}, \mathrm{N})$ \\
\hline
\end{tabular} & & & & & & \\
\hline
\end{tabular}

Table 5 Torque values obtained from experiments

\begin{tabular}{lllllll}
\hline $\begin{array}{l}\text { Blade } \\
\text { No. }\end{array}$ & & & \multicolumn{2}{l}{ Parameters } & \multicolumn{2}{l}{ Torque, $\mathbf{N m}$} \\
& $\begin{array}{l}\mathbf{P}_{\mathbf{1}}(\mathbf{\beta}), \\
\text { degree }\end{array}$ & $\begin{array}{l}\mathbf{P}_{\mathbf{2}}(\boldsymbol{\theta}), \\
\text { degree }\end{array}$ & $\begin{array}{l}\mathbf{P}_{\mathbf{3}}(\mathbf{h}), \\
\mathbf{m m}\end{array}$ & $\begin{array}{l}\mathbf{P}_{\mathbf{4}}(\mathbf{V}), \\
\mathbf{m} / \mathbf{s}\end{array}$ & $\begin{array}{l}\mathbf{P}_{\mathbf{5}}(\mathbf{N}), \\
\mathbf{r p m}\end{array}$ \\
\hline 1 & 18 & 97.2 & 75 & 0.5 & 150 & \\
2 & 18 & 102.6 & 93.75 & 0.94 & 180 & 47.95 \\
3 & 18 & 108 & 112.5 & 1.35 & 210 & 95.42 \\
4 & 18 & 113.4 & 131.2 & 1.78 & 240 & 166.92 \\
5 & 18 & 118.8 & 150 & 2.20 & 270 & 265.78 \\
6 & 19 & 97.2 & 93.75 & 1.35 & 240 & 90.73 \\
7 & 19 & 102.6 & 112.5 & 1.78 & 270 & 160.84 \\
8 & 19 & 108 & 131.2 & 2.20 & 150 & 130.39 \\
9 & 19 & 113.4 & 150 & 0.50 & 180 & 40.51 \\
10 & 19 & 118.8 & 75 & 0.94 & 210 & 44.08 \\
11 & 20 & 97.2 & 112.5 & 2.20 & 180 & 133.61 \\
12 & 20 & 102.6 & 131.2 & 0.50 & 210 & 41.23 \\
13 & 20 & 108 & 150 & 0.94 & 240 & 100.54 \\
14 & 20 & 113.4 & 75 & 1.35 & 270 & 81.57 \\
15 & 20 & 118.8 & 93.75 & 1.78 & 150 & 75.18 \\
16 & 21 & 97.2 & 131.2 & 0.94 & 270 & 98.82 \\
17 & 21 & 102.6 & 150 & 1.35 & 150 & 91.48 \\
18 & 21 & 108 & 75 & 1.78 & 180 & 71.88 \\
19 & 21 & 113.4 & 93.75 & 2.20 & 210 & 129.57 \\
20 & 21 & 118.8 & 112.5 & 0.50 & 240 & 40.34 \\
21 & 22 & 97.2 & 150 & 1.78 & 210 & 167.26 \\
22 & 22 & 102.6 & 75 & 2.20 & 240 & 118.28 \\
23 & 22 & 108 & 93.75 & 0.50 & 270 & 37.78 \\
24 & 22 & 113.4 & 112.5 & 0.94 & 150 & 47.54 \\
25 & 22 & 118.8 & 131.2 & 1.35 & 180 & 95.62 \\
\hline
\end{tabular}

\section{Analysis of Variance (ANOVA)}

Equations are preferably typed using word analysis of variance is a statistical tool used to examine the influence of design parameters on performance characteristics. By evaluating the contribution of design parameters in ANOVA, the degree of influence of design parameters on overall performance characteristics may be achieved. Fisher's F test data can determine whether these parameters will significantly affect performance characteristics at a certain level of confidence. The ANOVA method is used to detect the possible influence of changes in external variables (factors) on the observed samples [21] (Fisher, 1990). Analysis of variance is the most effective way to analyse more complex data sets. However, this method includes many different variants, each suitable for a specific experimental environment. In ANOVA, the DF of the quantity is the number of observations minus the number of parameters estimated from the data required to calculate the quantity. The premises mean square is then divided by the error mean square to obtain the variance ratio. This statistic was named ' $F$ ' (hence, 'F-test') in honour of Fisher by Snedecor [22]. The value of " $F$ " indicates the number of times that the mean square value between the premises exceeds the error mean square value.

The probability of obtaining statistical information of this order of magnitude by chance is obtained from the F distribution; that is, the probability is obtained from data with no significant difference 
between group means. Due to the combination of treatments used in the factorial experiment, the DF of the error term in ANOVA indicates the "power" of the experiment more importantly than the number of repetitions of [23].

The torque results obtained from the various combinations of clearance angle, blade angle, blade working depth, machine forward velocity, and rotary shaft speed are statistically analysed. The ANOVA result for the torque is given in Table 5. It appears from Table 6a, that the clearance angle and machine forward velocities and their interactions are most significant with $37.44 \%$ and $30.41 \%$, respectively. It is evident because torque is directly proportional to the machine forward velocity. The average $\mathrm{S} / \mathrm{N}$ (signal to noise) ratios for various factors are given in Table $6 \mathrm{~b}$, whereas confirmation test results are shown in Table $6 c$.

Table 6 Effect of five levels of various combinations of clearance angle, blade angle, blade working depth, machine forward velocity, and rotary shaft speed on torque

\begin{tabular}{cccccc}
\hline Factors & DF & SS & MSS & F-Value & $\begin{array}{c}\% \text { of } \\
\text { contribution }\end{array}$ \\
\hline$\beta$ & 4 & 341.3770 & 85.3442 & 4 & 37.44 \\
$\theta$ & 4 & 125.8236 & 31.4559 & 2 & 13.80 \\
$\mathrm{~h}$ & 4 & 23.5404 & 5.8851 & 1 & 2.58 \\
$\mathrm{~V}$ & 4 & 277.2624 & 69.3156 & 3 & 30.41 \\
$\mathrm{~N}$ & 4 & 143.7303 & 35.9325 & 2 & 15.76 \\
Error & 19 & & & & \\
Pooled & 6 & 149.364 & 24.894 & & \\
Error & \multicolumn{5}{c}{} \\
Total & 24 & 911.7337 & & \\
Abbreviations: DF= degrees of freedom, SS = Sum of squares, MS = Mean \\
square, F = variance ratio)
\end{tabular}

Table 7 Average $\mathrm{S} / \mathrm{N}$ ratio for Torque at various levels of factors

\begin{tabular}{cccccc}
\hline Level & $\begin{array}{l}\text { Clearance } \\
\text { angle (A) }\end{array}$ & $\begin{array}{l}\text { Blade } \\
\text { angle } \\
(\mathbf{B})\end{array}$ & $\begin{array}{c}\text { Blade } \\
\text { working } \\
\text { depth }(\mathbf{C})\end{array}$ & $\begin{array}{c}\text { Machine } \\
\text { forward } \\
\text { velocity } \\
\text { (D) }\end{array}$ & $\begin{array}{c}\text { Rotary } \\
\text { shaft speed } \\
(\mathbf{E})\end{array}$ \\
\hline 1 & 28.8301 & 33.6795 & 36.7953 & 30.5397 & 35.4355 \\
2 & 33.7119 & 33.7114 & 34.8578 & 35.9747 & 36.9830 \\
3 & 38.1246 & 38.1239 & 33.9658 & 39.1631 & 31.1963 \\
4 & 38.1240 & 38.1243 & 35.2683 & 32.6821 & 34.9999 \\
5 & 38.1239 & 33.2755 & 36.0274 & 38.5549 & 38.2999 \\
Delta & 9.2945 & 4.8488 & 2.8295 & 8.6234 & 7.1036 \\
Rank & 1 & 4 & 5 & 2 & 3 \\
\hline
\end{tabular}

Table 8 Confirmation test result for Torque

\begin{tabular}{cccc}
\hline & $\begin{array}{l}\text { Initial reading } \\
\text { of factors }\end{array}$ & $\begin{array}{l}\text { Optimum results } \\
\text { obtained } \\
\text { ANOM }\end{array}$ & $\begin{array}{l}\text { Improvement in } \\
\text { S/N Ratio }\end{array}$ \\
\hline $\begin{array}{c}\text { Level } \\
\text { Torque } \\
\text { (Nm) }\end{array}$ & $\begin{array}{c}\text { A1B5C5D5E5 } \\
\text { S/N }\end{array}$ & A3B4C1D3E5 & $49.06-48.49$ \\
Ratio & 485.78 & 283.64 & $=0.57$ \\
\hline
\end{tabular}

The effect of different control factors on torque is shown in factor responses. For better torque, it is found that the clearance angle and machine forward velocity leads to better control. The blade angle and rotary shaft speed is significant at the medium level to produce a high $\mathrm{S} / \mathrm{N}$ ratio, thus a better control on torque. The blade working depth is less contributing. The optimum levels of different control factors for maximum torque obtained are: A3B4C1D3E5, i.e., clearance angle is 20 degrees, blade angle is 113.4 degree, blade working depth is 75 $\mathrm{mm}$, machine forward velocity is $1.35 \mathrm{~m} / \mathrm{s}$, and rotary shaft speed is $270 \mathrm{rpm}$. These parameters are matched with blade no.14 (Table 2).

\section{Finite Element Analysis}

The blades are subjected to impact loads when they interact with the soils. This load mainly depends on the type and resistance force of the soil. The soil resistance for various types of soils is given in Table

9. It can be observed from this table that maximum soil resistance is offered by the heavy loam soil, producing 0.5 to $0.7 \mathrm{~kg} / \mathrm{cm} 2$ of soil loading. This force was considered during the finite element analysis of the blades.

\section{Table 9 Soil properties [24]}

\begin{tabular}{lll}
\hline Sl. No. & Type of soil & Soil resistance $\mathbf{( k g / \mathbf { c m } ^ { 2 } )}$ \\
\hline 1 & Sandy soil & 0.2 \\
2 & Sandy loam & 0.3 \\
3 & Slit loam & $0.35-0.5$ \\
4 & Clay & $0.4-0.56$ \\
5 & Heavy loam & $0.5-0.7$ \\
\hline
\end{tabular}

\subsection{Material properties of the blade}

The most commonly used material for the blade is high carbon steel (for high-grade blades). However, high carbon steel is costly, and its available yield strength is too high for the requirement. Fortunately, the yield strength and ultimate tensile strength of medium carbon steel are well suited for the requirement; hence medium carbon steel (AISI 1040) is considered for the analysis. The properties are given as follows: 
Material Name: Medium carbon steel (AISI 1040)

(0.29-0.54\% C, $0.6-1.65 \% \mathrm{Mn})$

Elastic modulus: $200 \mathrm{GPa}$

Poisson ratio: 0.29

Density: 7,87 (gm/cc)

Yield strength: $310 \mathrm{MPa}$

Ultimate Tensile strength: $565 \mathrm{MPa}$

\subsection{Analysis results}

All blades' displacement plots and stress distribution are obtained through structural analysis using finite element analysis software ANSYS. The maximum displacement and von Mises stress are also tabulated for all the twenty-five blades. The von Mises stress distribution is considered for verifying the design. Table 10 shows the different stress-strain values of all blades, and Fig 12-14 shows the stress analysis results of the optimised blade.

\section{Table 10 Analysis results}

\begin{tabular}{llll}
\hline $\begin{array}{l}\text { Blade } \\
\text { No. }\end{array}$ & $\begin{array}{l}\text { Displacement } \\
(\mathbf{m m})\end{array}$ & $\begin{array}{l}\text { von Mises } \\
\text { stress (MPa) }\end{array}$ & $\begin{array}{l}\text { Principal } \\
\text { stress (MPa) }\end{array}$ \\
\hline 1 & 1.4454 & 282.686 & 319.823 \\
2 & 1.09043 & 195.818 & 219.47 \\
3 & 0.842571 & 155.165 & 178.048 \\
4 & 0.659019 & 129.27 & 147.116 \\
5 & 0.522872 & 110.39 & 123.321 \\
6 & 0.897902 & 152.586 & 183.378 \\
7 & 0.730317 & 131.011 & 144.922 \\
8 & 1.18307 & 214.984 & 248.289 \\
9 & 0.843128 & 168.164 & 166.709 \\
10 & 0.671893 & 143.18 & 157.794 \\
11 & 1.19632 & 201.283 & 242.843 \\
12 & 0.93888 & 172.738 & 167.093 \\
13 & 0.739285 & 134.366 & 155.16 \\
14 & 0.585813 & 109.679 & 117.19 \\
15 & 0.940314 & 198.158 & 221.229 \\
16 & 0.797559 & 129.073 & 150.991 \\
17 & 1.31424 & 222.738 & 260.323 \\
18 & 0.985408 & 180.76 & 206.397 \\
19 & 0.752566 & 147.455 & 166.724 \\
20 & 0.587433 & 125.094 & 138.124 \\
21 & 1.02546 & 165.989 & 194.097 \\
22 & 0.82136 & 150.361 & 162.121 \\
23 & 0.656968 & 121.238 & 121.75 \\
24 & 1.05317 & 245.87 & 233.834 \\
25 & 0.783772 & 173.589 & 168.921 \\
\hline
\end{tabular}

From the statistical analysis using ANOVA, it has been found that the optimised blade has geometrical parameters and operating parameters, as shown in Table 2. These blade geometrical parameters coincide with those of blade no. 14. Finite element analysis confirms this observation by showing minimum von Mises stress in blade no. 14 (Table 10).

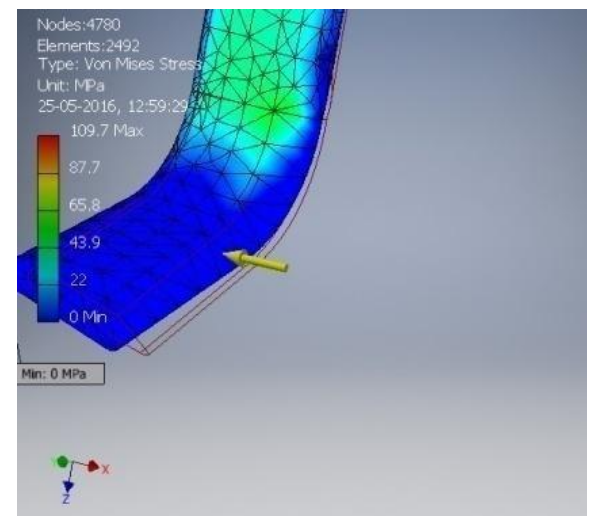

Fig. 12 Analysis Results: Von-Mises stress

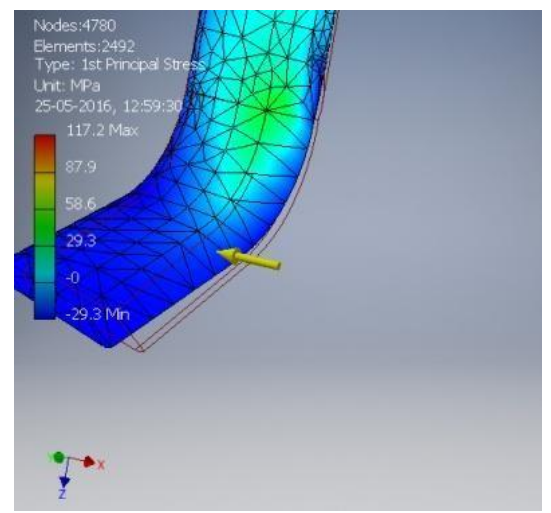

Fig. 13 Analysis Results: 1st Principal stress

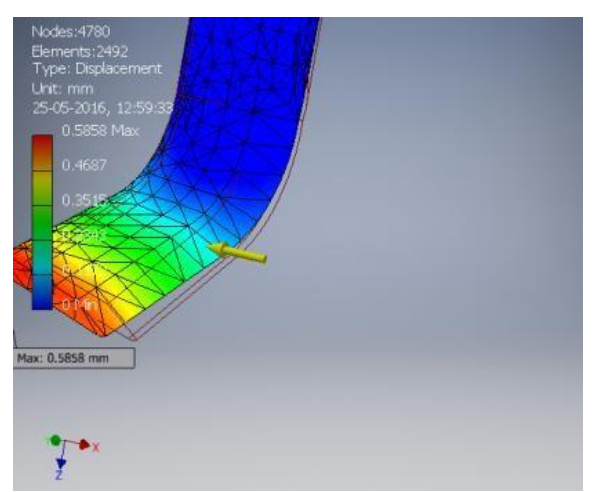

Fig. 14 Analysis Results: Displacements

Thus, it can be concluded that blade no. 14 is the most optimised blade in terms of geometrical properties and stress distribution obtained from ANOVA analysis and finite element analysis, respectively. The optimised blade's detailed design parameters and dimensions, i.e., blade no. 14, are shown in Table 11 and Fig. 15. 


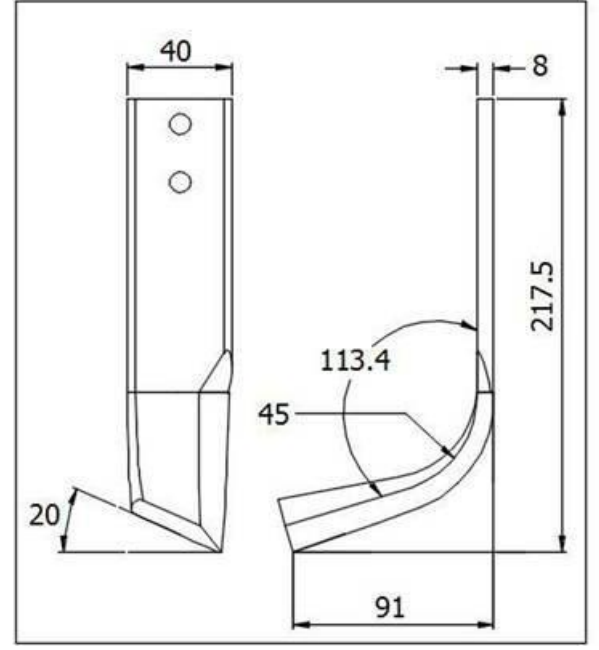

Fig 15 Final optimised blade

\section{Conclusions}

Optimal design parameters of the rotary tiller's blade were determined using ANOVA and validation of the results by finite element analysis to achieve maximum field efficiency, increase the selflife, and minimise the stresses or wear. This research mainly focuses on the design optimisation of the rotary tiller's L-shaped blades. It can be seen from the results that the clearance angle and forward machine speed can better control the torque. The blade angle and rotary shaft speed are significant at the medium level to produce a high $\mathrm{S} / \mathrm{N}$ ratio, thus a better control on torque. The blade working depth is less contributing. The results of this study may be verified by further trials on rotary tillers in an actual field condition according to the results offered in this paper.

\section{References}

1. Chertkiattipol S. and Nivamapa T. (2010), Variations of torque and specific tilling energy for different rotary blades. International Agricultural Engineering Journal Vol. 19(3):1-14

2. Siddique K. H. M, Johansen C, Turner N. C., Jeuffroy MH., Hashem A., Sarkar D., Gan Y. and Alghamdi S. S, (2012), Innovations in agronomy for food legumes: A Review, Agronomy for Sustainable Development, Vol. 32(1): 45-64.

3. Veerangouda M, Sushilendra E. R. and Anantachar M. (2011), Development and evaluation of multipurpose tool carrier for power tiller. Karnataka Journal of Agricultural Sciences, Vol. 24(5): 704-705.
4. Mairghany M., Yahya A., Adamb N. M., Ahmad S. M. S., Aimruna W. and Elsoragabya S. (2019), Rotary tillage effects on some selected physical properties of fine textured soil in wetland rice cultivation in Malaysia, Soil and Tillage Research, Vol. 194:1-11.

5. Topakci M., Celik H. K. and Yilmaz D. (2008), Stress analysis on transmission gears of a rotary tiller using finite element method. Akendiz Ünivresitesi Ziraat Fakultesi Dergisi, Vol. 21(2): 155-160.

6. Culpin C. (1981), Farm Machinery, Granada Technical Books Press, Spain, 10th edn

7. Yatsuk E. P., Panov I M., Efimov D N. (1981), Rotary soil working machines (construction, calculation and design). Amerined publishing company Pvt. Ltd., New Delhi, 1st edn.

8. Srivastava A. K., Georing C. E. and Rohrbach R. P. (2006), Engineering Principles of Agricultural Machines. St. Joseph Press, Michigan, 2nd edn.

9. Adams W. J. Jr. and Furlong D. B. (1959), Rotary Tiller in soil preparation. Agricultural Engineering, Vol. 40: 600-603 and 607.

10. Mahal J. S., Manes G.S., Apoorv P. (2012), Study on Blade Characteristics of Commercially Available Rotavators in Punjab, Agricultural Engineering Today, Vol. 36(3): 8-11.

11. Kepner R. A., Bainer R. and Barger E. L. (1978), Principles of farm machinery, AVI Publishing Inc, Westport, Conn.

12. Mandal S. K., Bhattacharyya B. and Mukherjee S. (2015), Design of Rotary Tiller's Blade Using Specific Work Method (SWM), Journal of Applied Mechanical Engineering, Vol. 4(164): $1-6$.

13. Kinzel G. L, Holmes R. and Huber S. (1981), Computer graphics analysis of rotary tillers. Transactions of the ASAE, 1392-1395 and 1399.

14. Chen J., Dai J. H., Pan C. G. and Gao L. (1993), Studies on the down-cut energy-saving rotary blades. Transactions of the Chinese Society of Agril Machinery, Vol. 24(1): 37- 42.

15. Kosutic S., Ivancan S. and Stefanek E. (1994), Reduced tillage in production of maise and spring barley in Posavina. In Proc. 22nd International Meeting on Agricultural Engineering, Opatija (Croatia), 1994, 371-376.

16. Mollazade K., Ali J. and Ebrahim E. (2010), Application of Dynamical Analysis to Choose Best Subsoiler's Shape using ANSYS. New York Science Journal, Vol. 3(3): 93-100.

17. Mandal S. K., Bhattacharyya B., Mukherjee S. and Maity A. (2015), Rotary Tiller's Blade using Finite Element Analysis (FEA), International Journal of Modern Studies in Mechanical Engineering, Vol. 1(1): 19-26, 2015.

18. Vegad Er. G. M. and Yadav R. (2018), Design Analysis and Optimization of Rotary Tiller Blades Using Computer Software, Agricultural Mechanization in Asia, Africa and Latin America, Vol. 49(1): 44-50.

19. ASAE Standards. Soil cone penetrometer, S313.2, St. Joseph, MI, USA $2002 b$. 


\section{Journal of Manufacturing Engineering, December 2021, Vol. 16, Issue. 4, pp 115-123}

20. ASAE Standards. EP542 Procedures for using and reporting data obtained with the soil cone penetrometer, St. Joseph, MI, USA, 2002a.

21. Fisher R A. (1990), Statistical methods, Experimental design and scientific inference. Oxford Science publications.

22. Snedecor G. W. and Cochran W. G. (1980), Statistical methods, Iowa State University Press, Ames, Iowa,7th edition.
23. Ridgman W J. (1975), Experimentation in Biology, Blackie, London.

24. Matin Md. A., John M. F., Jacky M. A. D. (2014), Furrow parameters in rotary strip-tillage: Effect of blade geometry and rotary speed, Biosystems Engineering, Vol. 118: 7-1 